\title{
How effectively are osteopathic medical students coping with a stressful life-style?
}

\author{
MARGOT E. KURTZ, PhD \\ RICHARD D. PAULSEN, EdD \\ DANIEL FERGUSON, PhD
}

Medical education has been described as an extremely intense and stressful experience. First- and second-year osteopathic medical students $(N=225)$ were surveyed to assess their perceptions of their own physical and psychological wellbeing, mechanisms they use to combat daily stress, their leisure activities, and the health-promoting behaviors in which they engage. This study found perceived physical and psychological well-being to be quite good, with more than $82 \%$ of respondents reporting "good" or "excellent" in both areas. Only $11 \%$ of students reported using tobacco, and the mean number of alcoholic drinks consumed per day was less than one. Most of the students reported that they exercised regularly and that they did not view sleep deprivation as a significant problem; however, the students did perceive the stress attributed to the demands of medical school as quite high.

The primary coping behaviors they used in response to stress included humor, leisure, exercise, and social activity. Smoking, using medication, and using illicit

From the Department of Family Medicine, Michigan State University - College of Osteopathic Medicine (Dr Kurtz) and the Department of Park and Recreation Resources, Michigan State University (Drs Paulsen and Ferguson), East Lansing, Mich.

Reprint requests to Richard D. Paulsen, EdD, Department of Park and Recreation Resources, 131 Natural Resources Bldg, East Lansing, MI 48824-1222. drugs were infrequently indicated as coping strategies. From a comprehensive perspective, student perceptions indicate that they are effectively coping with the stresses of medical education.

Medical education is perhaps the most intense and stressful of all occupational training experiences. ${ }^{1-4}$ Stress during medical school has been attributed to a wide variety of factors, including final examinations, the large amount of information to be mastered, the failure of the faculty to provide positive feedback, students' fear of failure, and the extremely long hours of work..$^{5,6}$ Sleep deprivation, identified as one of the most common problems medical students and physicians experience, has been shown to affect clinical capabilities. ${ }^{7,8}$

Psychosocial stress, overwork, and health problems have been linked to physician and medical student impairment. ${ }^{9}$ Anxiety and depression, the most common psychiatric problems observed in medical students, have been associated with the stresses of medical training. ${ }^{10}$ Thomas ${ }^{11}$ found that more than $3 \%$ of medical school graduates die prematurely and $10 \%$ fail to reach their full potential as physicians.

Substance abuse has been identified as a debilitating aspect of physicians' and medical students' lives; alcohol takes a large toll, followed by drug abuse. The research of Thomas 
and colleagues ${ }^{12}$ suggests that $10 \%$ of medical students become problem drinkers. Kay and associates ${ }^{13}$ reported that the medical students they surveyed slept too little, had poor diets, and believed that the medical school experience was detrimental to their health. Other primary concerns and stresses identified by medical students include lack of time for health-promoting activities such as recreation and social contact with family and friends and a preoccupation with studying to the exclusion of everything else, especially in the first year of medical school. ${ }^{14-16}$

Indeed, medical students are a population under stress. The literature is replete with reports on the unique stresses experienced by medical students and the impact these stresses have on their behaviors and lives. Some recent research has focused on health-promoting behaviors of medical students. Nevertheless, the available information has not been adequate to present a comprehensive picture of how medical students attempt to cope with the stresses in their daily lives. To shed some light on this situation, we designed a study to investigate the life-styles of first- and secondyear osteopathic medical students, the perceptions they have regarding their physical health and psychological well-being, the methods they use to combat stresses in their daily lives, and other life-style patterns such as nutrition, sleeping habits, alcohol and drug use, exercise, and leisure activities.

The evolution of the study reported here was influenced heavily by the work of Wolf and Kissling. ${ }^{1}$ In their study, they examined freshman medical students' stress-coping effectiveness in relation to physical and psychological health, sleep patterns, and physical, leisure, and recreational activities. We found multiple studies that describe high stress levels, substance abuse, and lack of time for recreation and social contact as significant issues among medical students. We therefore undertook the present study in an attempt to quantify these problems.

Three questions guided the study: What perceptions do first- and second-year medical students have regarding their physical health and psychological well-being? What mechanisms do they use to combat daily stresses? What leisure activities and health-promoting behaviors do they engage in?

\section{Subjects and methods \\ Study population}

The invited study sample comprised a class of 125 first-year osteopathic medical students (who had just completed their first year of medical training) and a class of 100 second-year osteopathic medical students (who were completing the last term of their second year). Both classes had participated in a unit of a course on physician/student self-care in their first term of training. This unit made them aware of the stresses inherent in medical school, the unique stresses of medical practice, statistics on medical student/physician impairments, as well as the impact these stresses had on health and well-being.

\section{Questionnaire}

The study sample was surveyed by means of a questionnaire whose design evolved from an extensive review of the literature. The questionnaire consisted of multiple-choice items designed to yield scaled responses in four major categories: physical health, psychological wellbeing, stress and stress-coping mechanisms, and life-style activities. It assessed major lifestyle areas such as smoking, the use of alcohol, the use of illicit drugs, sleep, nutrition, stress and coping, body build, exercise, and leisure activities as well as physical and psychological well-being. The questionnaire also elicited demographic information regarding gender, age, and marital status.

After a pretest was conducted, the questionnaire was revised, and, at the end of a class session, it was administered to those students who had consented to participate in the study. Students were assured that their responses would remain anonymous. They were instructed to answer all questions on the basis of their current situations. The terms "leisure time" and "leisure activities, discretionary time" were defined for them. It took approximately 35 minutes for students to complete the questionnaire. 
Table 1

Differences in Smoking Frequency Between Males and Females and Between First- and Second-Year Osteopathic Medical Students $(\mathrm{N}=224)$

\begin{tabular}{|c|c|c|c|c|c|c|c|c|}
\hline \multirow{2}{*}{$\begin{array}{l}\text { Cigarettes } \\
\text { smoked } \\
\text { per day }\end{array}$} & \multicolumn{2}{|c|}{$\begin{array}{l}\text { Male Students } \\
\quad(n=149)\end{array}$} & \multicolumn{2}{|c|}{$\begin{array}{l}\text { Female students } \\
\qquad(\mathbf{n}=\mathbf{7 5})\end{array}$} & \multicolumn{2}{|c|}{$\begin{array}{l}\text { First-year students } \\
\quad(n=124)\end{array}$} & \multicolumn{2}{|c|}{$\begin{array}{l}\text { Second-year students } \\
\qquad(\mathrm{n}=100)\end{array}$} \\
\hline & No. & $\%$ & No. & $\%$ & No. & $\%$ & No. & $\%$ \\
\hline 0 & 141 & 94.63 & 63 & 84.00 & 112 & 90.32 & 92 & 92.00 \\
\hline 1 & 3 & 2.01 & 1 & 1.33 & 3 & 2.41 & 1 & 1.00 \\
\hline 2 & 1 & .06 & 0 & 0 & 1 & 0.08 & 0 & 0 \\
\hline 3 & 0 & 0 & 0 & 0 & 0 & 0 & 0 & 0 \\
\hline 4 & 0 & 0 & 1 & 1.33 & 1 & 0.08 & 0 & 0 \\
\hline 7 & 0 & 0 & 1 & 1.33 & 1 & 0.08 & 0 & 0 \\
\hline 8 & 0 & 0 & 1 & 1.33 & 0 & 0 & 1 & 1.00 \\
\hline 10 & 2 & 1.34 & 1 & 1.33 & 1 & 0.08 & 2 & 2.00 \\
\hline 15 & 0 & 0 & 2 & 2.66 & 2 & 0.16 & 0 & 0 \\
\hline 20 & 0 & 0 & 3 & 4.00 & 2 & 0.16 & 1 & 1.00 \\
\hline 25 & 2 & 1.34 & 1 & 1.33 & 1 & 1.33 & 2 & 2.00 \\
\hline 30 & 0 & 0 & 1 & 1.33 & 0 & 0 & 1 & 1.00 \\
\hline \multirow{3}{*}{$\begin{array}{l}\text { Total No. who } \\
\text { smoked } \\
\text { Mean No. who } \\
\text { smoked }\end{array}$} & & & & & & & & \\
\hline & 8 & & 12 & & 12 & & 8 & \\
\hline & 9.38 & & 14.58 & & 10.08 & & 16.3 & \\
\hline SD & 10.38 & & 8.81 & & 8.67 & & 10.25 & \\
\hline
\end{tabular}

\section{Results}

A total of 225 first- and second-year osteopathic medical students were invited to participate in the study. Of that group, 224 students completed questionnaires, all of which were usable. Therefore, the response rate for the analysis was $99.5 \%$. The class of first-year students comprised 46 women and 79 men, and the second-year class, 29 women and 71 men. The average age of both classes was 26 years.

\section{Smoking}

In examining the students' perceptions of their physical well-being, it was found that a large majority $(89 \%)$ of them said they did not currently smoke tobacco. The $11 \%$ who did smoke averaged 11 cigarettes, or half a package, per day (SD $=9.6$ ). Table 1 provides a truer picture of the smoking patterns for the respondents according to sex and by year in medical school. Clearly, few students in the two classes (4\%) smoked more than ten cigarettes per day. It should be noted that $90 \%$ of the students did respond to this survey item. It is also noteworthy that while the second-year students had a dramatic increase in the mean number of cigarettes smoked per day over the firstyear students, there was a $25 \%$ decrease in the number of second-year students who smoked.

\section{Exercise}

The average class member reported exercising vigorously for 20 minutes or more at least three times per week; $68 \%$ of the respondents perceived themselves to be active to extremely active individuals. Although the female students exercised slightly less than the male students and second-year students slightly less than first-year students, these differences were not significant.

\section{Nutrition}

With regard to their nutrition and personal body build, the group as a whole rated themselves positively. Among the respondents, $76 \%$ perceived their diets as nutritionally sound. Those who reported snacking $(79 \%)$ averaged $1.26(\mathrm{SD}=1.56)$ snacks (potato chips, candy, cookies) per day. Nearly $99 \%$ rated themselves as having at least an average physical appearance, with $65 \%$ stating they thought themselves to be either "attractive" or "very attractive." 
Table 2

Feelings of Medical Students About Their Psychological State

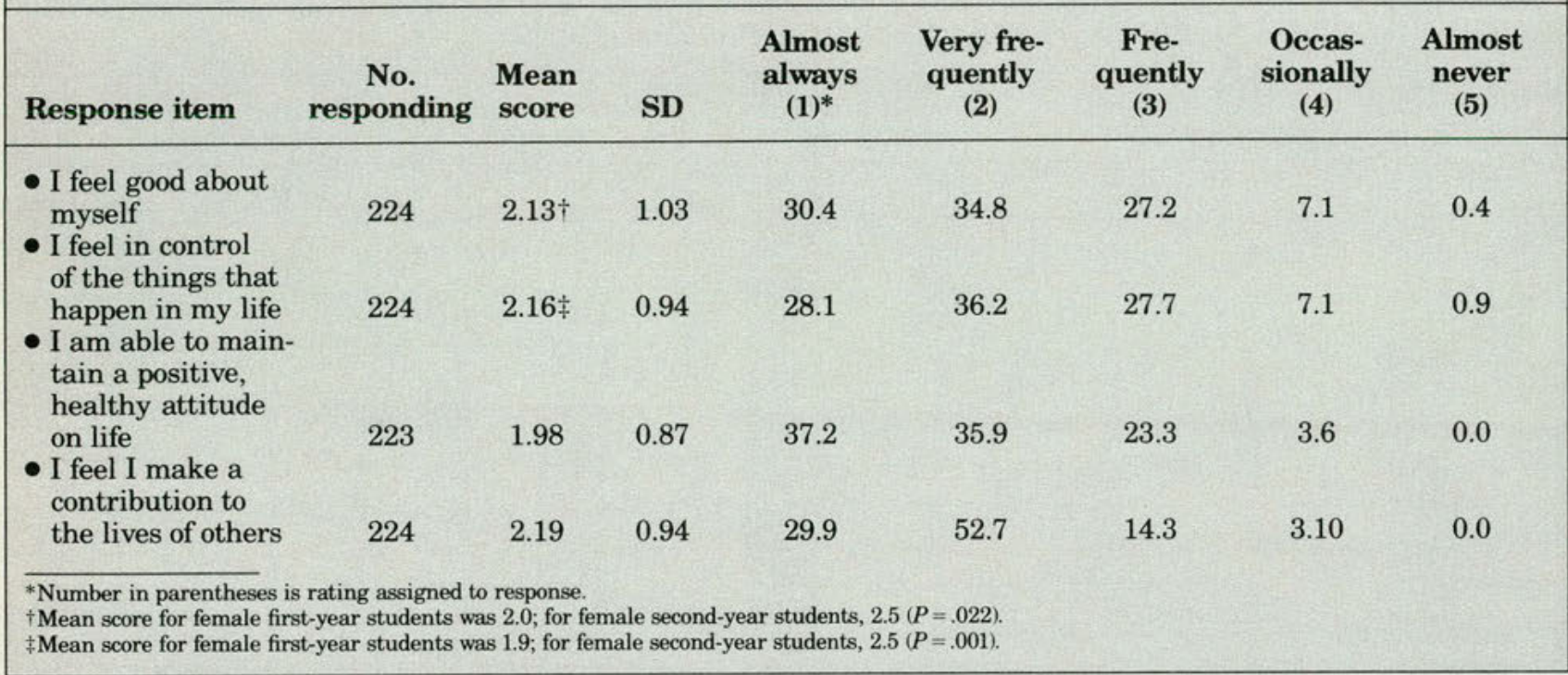

\section{Sleep}

Sleep deprivation is one area of physical wellbeing that has been reported to cause a problem for medical students. However, the two classes of osteopathic medical students surveyed reported an average of 6.8 hours of sleep per night $(\mathrm{SD}=1.8)$, with sleep being interrupted on an average of 2.2 nights each week $(\mathrm{SD}=2.0)$ and with an average number of waking times of $1.6(\mathrm{SD}=1.2)$. It is noteworthy that there were no significant differences in reported sleep patterns between either firstand second-year students or between men and women.

\section{Alcohol use}

Alcohol consumption can be a major factor affecting physical well-being. In the present study, it was found that $17 \%$ of the students did not drink alcohol at all, and, of those who did, the mean number of drinks was less than one per day and slightly more than four per week. Male students consumed alcohol twice as much as female students, with a mean number of drinks per week of $4.83(\mathrm{SD}=4.55)$ compared with $2.67(\mathrm{SD}=1.95)$ per week for the women $(P=.001)$. First-year female students on average consumed three drinks per week, while second-year female students consumed just two drinks per week $(P=.04)$. Drinking habits of male students in both classes were almost identical.

\section{Physical well-being}

In response to questions regarding physical well-being, fully $88 \%$ of the students reported themselves to be in "excellent" or "good" physical health, with the remaining $12 \%$ reporting "average" or "fair" physical health. Maintenance of physical health was reflected in $59.4 \%$ of all students having had a medical checkup during the previous year and $67.9 \%$ having had a dental checkup during the past year.

\section{Psychological health}

Several survey items were aimed at assessing the psychological health of the students. Eighty-two percent of the respondents reported their psychological (emotional) health to be either "excellent" or "good." None of the students thought that he or she was in "poor" psychological health, and $18 \%$ indicated "average" to "fair" psychological health.

Perceptions that reflect students' psychological well-being are presented in Table 2 . This table displays that, as a group, the students felt good about themselves; they felt in control of things that happen in their lives; they were able to maintain a positive, healthy attitude about life; and they thought that they were 
Table 3

Medical Student Ratings According to the Extent to Which Various Emotions Were Manifested During the Previous Week

\begin{tabular}{|lccccccccc|}
\hline & & & & \multicolumn{5}{c}{ Ratings (\%) } \\
\cline { 6 - 9 } Emotions & $\begin{array}{c}\text { No. } \\
\text { responding }\end{array}$ & $\begin{array}{c}\text { Mean } \\
\text { rating }\end{array}$ & SD & $\begin{array}{c}\text { Always } \\
(\mathbf{1})^{*}\end{array}$ & $\begin{array}{c}\text { Frequently } \\
\text { (2) }\end{array}$ & $\begin{array}{c}\text { Sometimes } \\
\text { (3) }\end{array}$ & $\begin{array}{c}\text { Infre- } \\
\text { quently } \\
\text { (4) }\end{array}$ & $\begin{array}{c}\text { Never } \\
\text { (5) }\end{array}$ \\
\hline Contentment & 224 & 2.38 & 0.50 & 4.5 & 45.1 & 31.7 & 14.7 & 4.0 \\
Affection & 224 & 2.41 & 0.92 & 12.9 & 47.8 & 26.8 & 9.8 & 2.7 \\
Vigor & 224 & 2.50 & 0.79 & 7.6 & 43.8 & 40.2 & 7.1 & 1.3 \\
Joy & 221 & 2.52 & 0.77 & 7.2 & 42.5 & 41.6 & 7.7 & 0.9 \\
Anxiety & 222 & 2.59 & 0.89 & 8.1 & 42.3 & 32.0 & 16.7 & 0.9 \\
Guilt & 222 & 3.64 & 1.03 & 1.4 & 14.0 & 27.0 & 34.2 & 23.4 \\
Hostility & 224 & 3.66 & 0.94 & 0.9 & 12.1 & 25.0 & 43.8 & 18.2 \\
Depression & 223 & 3.74 & 0.97 & 0.4 & 11.2 & 28.3 & 33.6 & 26.5 \\
*Numbers in parentheses are ratings assigned to response. & & & & & & & \\
\hline
\end{tabular}

making a contribution to the lives of others.

The ratings in Table 3 help provide an affective dimension to the students' sense of psychological well-being. The overall responses to each of these items were quite positive.

\section{Stress and stress-coping mechanisms}

Stress of medical education was believed to be extreme; $57.6 \%$ of the students reported a high or very high level of stress in their lives, and $37 \%$ reported a moderate level. Both men and women in the second-year class reported a significantly higher level of stress than their firstyear counterparts, as shown in Table 4. Yet, in spite of this high stress level, $93 \%$ of all students rated their effectiveness in dealing with stress as at least "average," and $70 \%$ gauged their ability to cope with stress as "good" or "excellent." Men in both classes rated their ability to deal with stress significantly higher than did the women in both classes $(P$ $=.04)$.

The academic rigors of medical education appeared to be particularly strong during the second year. This situation caused greater internal conflict between the pressures of academic demands and the students' desire to engage in leisure activities. Both male and female second-year students reported significantly greater internal conflict with respect to leisure than did their first-year counterparts. This relationship as well as other sig-

\begin{tabular}{|c|c|c|c|c|}
\hline \multicolumn{5}{|c|}{$\begin{array}{l}\text { Table } 4 \\
\text { Levels of Perceived Stress Among First- and } \\
\text { Second-Year Osteopathic Medical Students }\end{array}$} \\
\hline $\begin{array}{c}\text { Sex/ } \\
\text { Year of } \\
\text { Osteopathic } \\
\text { Medical } \\
\text { School }\end{array}$ & No. & $\begin{array}{l}\text { Mean } \\
\text { level } \\
\text { of } \\
\text { stress* }\end{array}$ & SD & $\begin{array}{c}P \\
\text { value }\end{array}$ \\
\hline \multicolumn{5}{|l|}{ Male students } \\
\hline First year & 77 & 2.54 & 0.78 & \\
\hline Second year & 71 & 2.23 & 0.70 & .01 \\
\hline \multicolumn{5}{|l|}{$\begin{array}{l}\text { Female } \\
\text { students }\end{array}$} \\
\hline First year & 46 & 2.58 & 0.80 & \\
\hline Second year & 29 & 2.00 & 0.70 & .001 \\
\hline \multicolumn{5}{|c|}{$\begin{array}{l}\text { *Based on response to question, How would you rate the level of stress } \\
\text { in your life at the present time? } \\
\text { Rating: } 1=\text { very high; } 2=\text { high; } 3=\text { moderate; } 4=\text { low; } 5=\text { very low. }\end{array}$} \\
\hline
\end{tabular}

nificant variances between classes and between genders is illustrated in Table 5 .

To investigate the behaviors medical students use to cope with stress, we examined a series of 17 coping mechanisms, summarized in Table 6 . The items are ranked by mean frequency of occurrence. The coping behaviors are rank ordered with the most frequently used behavior listed first. The most frequently used coping behaviors included: sense of humor (mean 2.19, $\mathrm{SD}=0.82)$; leisure (mean 2.38, $\mathrm{SD}=0.50)$; exercise (mean $2.41, \mathrm{SD}=0.99$ ); 
Table 5

Differences Between First- and Second-Year Students by Gender With Respect to Medical Education and Leisure

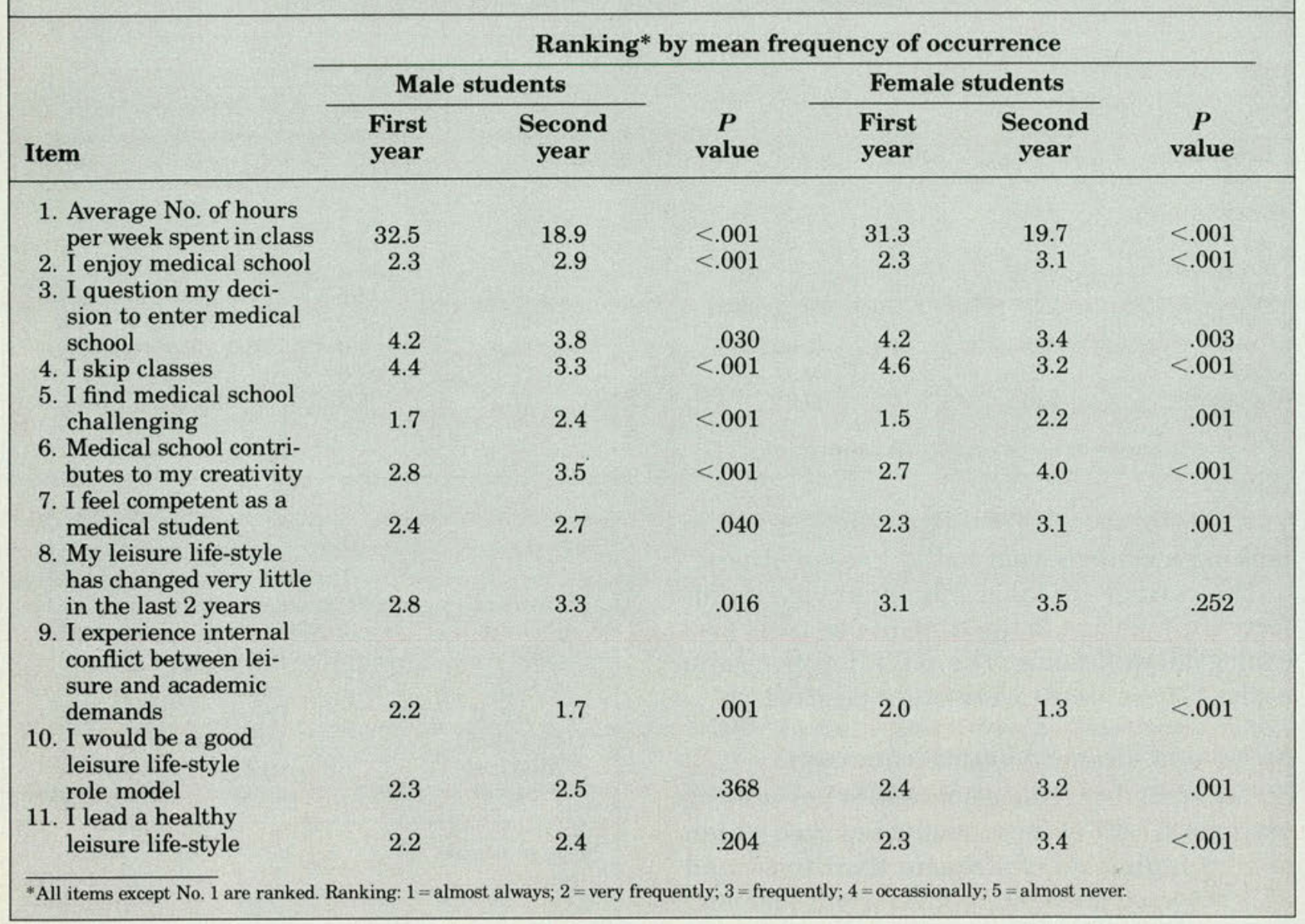

and social activities (mean 2.61, SD 0.81). Infrequently used behaviors used were: smoking (mean 4.67, $\mathrm{SD}=0.86$ ); medication (mean $4.68, \mathrm{SD}=0.73$ ); and drugs (mean $4.70, \mathrm{SD}$ $=0.68$ ).

Subjects in this study reported spending an average of 12.3 hours (SD $=8.9$ hours) per week at leisure, with an average of 12.4 additional hours (SD $=10$ hours) of discretionary time per week that could be used for leisure pursuits. Male students as a group reported having a greater number of hours (mean 13.9, $\mathrm{SD}=11.9$ ) of leisure time per week than female students as a group (mean 10.3, SD = 6.3) $(P=.01)$.

Sixty-two percent of the subjects perceived that they lead healthy leisure life-styles, while $19 \%$ were neutral on this response item. The remaining $19 \%$ perceived that they do not have a leisure life-style that they would view as healthy.

The findings on this item were consistent with the fact that $54 \%$ of the group viewed themselves as good, healthy life-style role models for patients. Perhaps most interesting about this segment of the data is the fact that $89 \%$ of all the students agreed or strongly agreed that physicians should role model healthy leisure life-styles for their patients, and less than $2 \%$ disagreed with this concept. Some significant differences exist between firstand second-year students regarding these items (Table 5).

When the students were asked to indicate which of 12 items restricted them from leading a healthy leisure life-style, academic demands and lack of free time emerged as the most restrictive, followed by financial constraints. As indicated in Table 7, the other 
nine items were not perceived to be very restrictive.

\section{Discussion}

Behaviors students reported as directly affecting physical health support their collective perception of very good physical condition. Cigarette smoking was a behavior in which only $9.7 \%$ of the first-year students and $8.0 \%$ of the second-year students indulged. Female students as a group are of particular interest: $16 \%$ of the women reported smoking compared with only $5.4 \%$ of their male counterparts. Although these percentages for both classes are higher than those reported by Maynard and colleagues $(5 \%),{ }^{17}$ they are within the range reported by Coe and coworkers ( $7 \%),{ }^{18}$ by Sobal ( $11 \%$ first semester $10 \%$ second semester), ${ }^{19}$ and by Maddux and associates $(12 \%) \cdot{ }^{20}$ It is encouraging that cigarette smoking among medical students appears to be decreasing since 1977 , when Thomas ${ }^{12}$ reported $18 \%$ of freshmen and $40 \%$ of seniors smoked.

The amount of vigorous exercise was similar for first- and second-year students and for male and female students. This level of exercise of medical students was consistent with that found by other researchers. ${ }^{1,21}$

Although $76 \%$ of the total sample perceived their diets as sound, the students were not requested to specify the contents of their meals. It is entirely possible that their perceptions were not realistic. Nonetheless, their perceptions at least reflect the findings of Maynard and coworkers ${ }^{17}$ that medical students (89\%) believe that proper nutrition is important to protect good health. Sobal ${ }^{19}$ also reported that $74 \%$ of first-semester students and $63 \%$ of second-semester students ate sensibly to protect their health.

Getting enough sleep has been identified as an important protective behavior for health. Maynard and colleagues ${ }^{17}$ reported that medical students (78\%) thought that adequate sleep was an important behavior in protecting health. The amount of sleep time reported by students in our study (6.8 hours) was similar for first- and second-year groups, with no differences between men and women. Other researchers have reported approximately the same average amount of sleep: Parkerson and coworkers ${ }^{21}$ reported an average of more than 6 hours, and Wolf and Kissling ${ }^{1}$ reported an average of 7 hours. Students in our sample reported fewer nights of interrupted sleep than did students surveyed by Wolf and Kissling ${ }^{1}$ ( 0.7 interruptions per night). These findings reinforce the findings of the study by Sobal. ${ }^{19}$

Alcohol use in our sample was similar to that for first-year students surveyed by Maynard and colleagues ${ }^{17}$ ( $80 \%$ of all students). They also found that male students consume more alcohol than female students. Other studies have identified alcohol use by medical students ranging from $63.3 \%{ }^{21}$ to $91 \% .^{20}$ These findings reflect the attitudes uncovered by Maynard and colleagues. ${ }^{17}$ In their study, only $10 \%$ of first-year medical students viewed alcohol abstinence or moderation in consumption as behavior important to protecting health.

Students had strong, positive perceptions of their psychological well-being. The decline in general health-including psychological health of female students-during the first year of medical school reported by Wolf and Kissling ${ }^{1}$ was generally not reported by our sample. The exceptions were a decline reported by first- and second-year female students in feeling good about themselves and in feeling in control of things that happen in their life.

As a group, the students in our survey had positive perceptions of both their physical health and psychological well-being. Their perceptions were supported by their reported behaviors that influence both physical and psychological health. These reported behaviors were generally consistent with those reported by other researchers. Of concern are three areas related to the physical and psychological health of female students, specifically a higher rate of smoking than their male counterparts, the significant decline in feeling good about themselves in the second year of medical school, and the significant decline in feelings of being in control of life events.

Students rated perceived stress as high, increasing between the first and second years. This finding supports a similar one reported by Wolf and Kissling. ${ }^{1}$ As a group, students 


\begin{tabular}{|c|c|c|c|c|c|c|c|}
\hline \multirow[b]{3}{*}{ Behavior } & \multicolumn{6}{|c|}{$\begin{array}{l}\text { Table } 6 \\
\text { Mechanisms Used by Osteopathic Medical Students (\%) To Cope } \\
\text { With Stress in Rank Order }(\mathrm{N}=224)\end{array}$} & \multirow[b]{3}{*}{$\begin{array}{c}\text { Never } \\
\text { (5) }\end{array}$} \\
\hline & \multirow[b]{2}{*}{$\begin{array}{l}\text { Mean } \\
\text { rank } \\
\text { order }\end{array}$} & \multirow[b]{2}{*}{ SD } & \multicolumn{4}{|c|}{ Ranked order by students (\%) } & \\
\hline & & & $\begin{array}{c}\text { Always } \\
\text { (1) }\end{array}$ & $\begin{array}{l}\text { Fre- } \\
\text { quently } \\
(2)\end{array}$ & $\begin{array}{l}\text { Some- } \\
\text { times } \\
(3)\end{array}$ & $\begin{array}{l}\text { Infre- } \\
\text { quently } \\
\text { (4) }\end{array}$ & \\
\hline Sense of humor & 2.19 & 0.82 & 20.7 & 44.1 & 20.6 & 4.1 & 0.5 \\
\hline Leisure & 2.38 & 0.50 & 17.9 & 49.1 & 25.7 & 7.3 & 0.0 \\
\hline Exercise & 2.47 & 0.99 & 17.1 & 34.7 & 35.1 & 9.9 & 3.2 \\
\hline Social activities & 2.61 & 0.81 & 6.7 & 39.5 & 39.9 & 13.5 & 0.4 \\
\hline Sleeping & 3.01 & 0.97 & 4.5 & 26.6 & 38.7 & 23.4 & 0.8 \\
\hline Work & 3.21 & 1.00 & 3.6 & 19.3 & 39.9 & 13.5 & 0.4 \\
\hline Sex & 3.22 & 1.02 & 4.1 & 19.5 & 38.0 & 26.2 & 12.2 \\
\hline Eating & 3.24 & 1.09 & 3.6 & 21.2 & 36.5 & 26.6 & 11.7 \\
\hline Vacation & 3.39 & 0.94 & 4.5 & 9.9 & 36.9 & 39.2 & 9.5 \\
\hline Readjusting life- & 3.42 & 0.86 & 0.5 & 131 & 39.2 & 36.5 & 20.8 \\
\hline Drinking & $\begin{array}{l}0.42 \\
3.83\end{array}$ & $\begin{array}{l}0.00 \\
1.02\end{array}$ & $\begin{array}{l}0.0 \\
1.8\end{array}$ & 9.0 & 24.7 & 33.2 & 31.4 \\
\hline Caring for a pet & 3.98 & 1.30 & 5.6 & 14.0 & 11.2 & 15.4 & 53.8 \\
\hline Crying & 4.02 & 0.87 & 0.0 & 5.0 & 23.9 & 36.5 & 34.7 \\
\hline Caring for plants & 4.33 & 0.90 & 0.9 & 4.1 & 11.7 & 27.4 & 55.9 \\
\hline Smoking & 4.67 & 0.86 & 1.8 & 4.1 & 3.2 & 7.2 & 83.7 \\
\hline Medication & 4.68 & 0.73 & 0.9 & 2.3 & 4.1 & 13.1 & 79.7 \\
\hline Drugs & 4.70 & 0.68 & 0.5 & 1.8 & 4.5 & 13.5 & 79.7 \\
\hline
\end{tabular}

\begin{tabular}{|c|c|c|c|c|c|c|c|c|}
\hline \multicolumn{9}{|c|}{$\begin{array}{c}\text { Table } 7 \\
\text { Factors Restricting Osteopathic Medical Students (\%) } \\
\text { From Leading a Healthy Leisure Life-style }\end{array}$} \\
\hline \multirow[b]{2}{*}{ Restriction } & \multirow[b]{2}{*}{$\begin{array}{l}\text { No. } \\
\text { res- } \\
\text { ponding }\end{array}$} & \multirow[b]{2}{*}{$\begin{array}{c}\text { Mean } \\
\text { extent }\end{array}$} & \multirow[b]{2}{*}{ SD } & \multicolumn{5}{|c|}{ Extent factors restrict students (\%) } \\
\hline & & & & $\begin{array}{l}\text { Very } \\
\text { much } \\
(1)\end{array}$ & $\begin{array}{c}\text { Much } \\
(2)\end{array}$ & $\begin{array}{c}\text { Some } \\
(3)\end{array}$ & $\begin{array}{l}\text { Not } \\
\text { much } \\
(4)\end{array}$ & $\begin{array}{c}\text { None } \\
\text { (5) }\end{array}$ \\
\hline Academic demands & 224 & 1.71 & 0.84 & 50.0 & 33.5 & 13.4 & 2.7 & 0.4 \\
\hline Lack of free time & 224 & 1.96 & 0.95 & 37.9 & 36.6 & 19.6 & 4.5 & 1.4 \\
\hline Financial constraints & 224 & 2.87 & 1.22 & 17.4 & 18.8 & 32.1 & 21.9 & 9.8 \\
\hline Work & 222 & 3.53 & 1.37 & 12.2 & 8.6 & 25.1 & 18.0 & 35.1 \\
\hline \multicolumn{9}{|l|}{ Lack of facilities for } \\
\hline pursuing interests & 222 & 3.96 & 0.92 & 0.9 & 5.0 & 23.9 & 37.3 & 32.9 \\
\hline Lack of motivation & 224 & 3.98 & 0.97 & 0.4 & 5.8 & 27.7 & 27.3 & 38.8 \\
\hline \multicolumn{9}{|l|}{ Obligations to others } \\
\hline outside my family & 221 & 4.03 & 0.97 & 1.8 & 3.2 & 24.4 & 30.3 & 40.3 \\
\hline Obligations to spouse & 204 & 4.24 & 1.03 & 1.0 & 6.9 & 19.1 & 14.2 & 58.8 \\
\hline Obligations to parents & 223 & 4.29 & 0.95 & 1.3 & 2.2 & 15.7 & 26.8 & 53.8 \\
\hline Lack of leisure skills & 224 & 4.40 & 0.77 & 1.8 & 12.5 & 29.5 & 56.2 & 0.0 \\
\hline Health limitations & 224 & 4.58 & 0.78 & 0.9 & 2.2 & 5.8 & 18.3 & 72.8 \\
\hline Obligations to children & 208 & 4.67 & 0.83 & 1.4 & 4.3 & 3.4 & 7.2 & 83.7 \\
\hline
\end{tabular}


rated their ability to deal with stress as "good" to "excellent." The only significant differences were between male and female students of both classes. Male students rated their effectiveness in coping with stress higher than did their female counterparts.

Although specific sources of stress were not investigated in the current study, behaviors used to control stress were examined. It is encouraging that the most frequently used coping mechanisms (sense of humor, leisure, exercise, and social activities) were positive approaches to combating stress. Equally encouraging is the infrequent use of negative mechanisms (smoking, medication, and drugs) to deal with stress.

It should be noted that, although $83 \%$ of the students reported drinking alcohol, $64.6 \%$ reported that they infrequently or never drink to cope with stress. Identification of these major coping activities is consistent with positive physical health activities reported by students. It is not surprising that similar activities (recreation and entertainment, social interaction, and exercise) have been identified as uplifting (pleasant, happy, or satisfying experiences) by senior medical students. ${ }^{22}$

Other studies ${ }^{1,23}$ have identified leisure or recreational activities as important elements of students' life-style. Wolf and coworkers ${ }^{23}$ reported that no significant relationship existed between weekday leisure activities and responses to coping indicators of first-year medical students. However, the osteopathic medical students surveyed in our study reported leisure and leisure-related activities as used frequently to cope with stress. This finding tends to support the importance of leisure activities for those persons who must function under considerable stress.

Students in our survey reported spending fewer hours per week in leisure or recreational activities than did the students surveyed by Wolf and Kissling ${ }^{1}$ (12.3 vs 15.7 hours per week). No significant differences were found in the amount of time spent in leisure between first- and second-year students, which is generally consistent with the findings of Wolf and Kissling. ${ }^{1}$ One interesting difference is that female students reported spending less time in leisure than male students. Although there may be many reasons for this difference, one intriguing explanation is the influence of sex roles and socialization on leisure behavior. ${ }^{24,25}$

Both first- and second-year students agreed that leisure activities are beneficial to health and that physicians should provide a role model of healthy leisure life-styles for their patients. It is interesting that students expressed internal conflict between leisure and academic demands during their second year of medical school, although they indicated that their leisure life-styles had changed little. Students may have experienced stress related to a conflict between the desire for personal time and the academic demands confronting them during the second year of study.

Female students expressed a significant difference in their perceptions of their leisure lifestyles between the first and second years. These differences indicate student perceptions of the value of leisure participation and, to a certain extent, their inability to derive the desired benefits from such activity. It would be interesting to determine if these conflicts continue throughout medical education and into physician practice.

\section{Summary}

The general profile of the osteopathic medical students we surveyed is not indicative of the troubled students reported in other studies who were deprived of sleep, ${ }^{7,8,13}$ experienced health problems, ${ }^{9}$ had psychiatric difficulties, ${ }^{10}$ abused alcohol and drugs, ${ }^{12}$ or consumed poor diets. ${ }^{13}$ Although some gender differences were noted, overall the osteopathic medical students surveyed presented positive perceptions of their physical health and psychological wellbeing. Activities that support good health were the most commonly used methods for coping with stress. Many of these activities were leisure-related, indicating that leisure opportunities may serve as significant deterrents to the negative effects of stress.

1. Wolf T, Kissling GE: Changes in lifestyle characteristics, health, mood of freshman medical students. J Med Educ 1984;59:809-814. 
2. Wallis C: Medical school, heal thyself. Time, May 23, 1983, p 54 .

3. Knight JA: Medical students, in Callan J (ed): The Physician: A Professional Under Stress. New York, Appleton-CenturyCrofts, 1983.

4. Knight JA: A Doctor-To-Be Coping With the Trials and Triumphs of Medical School. New York, Appleton-Century-Crofts, 1981.

5. Adsett CA: Psychological health of medical students in relation to the medical education process. J Med Educ 1968;43:728734 .

6. Hunter RC, Prince RH, Schmeartzman AE: Comments on emotional disturbances in a medical undergraduate population. Can Med Assoc J 1961;83:989-992.

7. Friedman RC, Kornfield DS, Bigger RJ: The intern and sleep loss. N Engl J Med 1971;285:201-203.

8. Friedman RC, Kornfield DS, Bigger RJ: Psychological problems associated with sleep deprivation in interns. $J$ Med Educ 1973;48:436-441.

9. Roeske NC: Stress and the physician. Psychiatric Annals 1981;11(7):10-32.

10. Kris K: Distress precipitated by psychiatric training among medical students. Am J Psychiatry 1986;143:1432-1435.

11. Thomas CB: What becomes of medical students: The dark side. Johns Hopkins Med J 1976;138:185-195.

12. Thomas RB, Luber A, Smith JA: A survey of alcohol and drug abuse in medical students. Dis Nerv Syst 1977;38:41-43.

13. Kay J, Howard T, Welch G: Health habits of medical students: Some perils of the profession. J Am Coll Health Assoc 1980;28:238-239.

14. Edwards M, Limet C: Problems and concern among medical students. $J$ Med Educ 1975;51:619-625.

15. Adsett CA: Psychological health of medical students in relation to the medical education process. $J$ Med Educ 1968;43:728734.

16. Coburn D, Jovaisas AV: Perceived sources of stress among first year medical students. J Med Educ50:589-595.

17. Maynard L, Goldberg R, Ockene J, et al: Behaviors and attitudes among medical students concerning cigarette smoking and alcohol consumption. J Med Educ 1986;61:921-922.

18. Coe RM, Miller DK, Wolff M, et al: Attitudes and health promoting behavior of medical and law students. Am J Public Health727.

19. Sobal J: Health protective behaviors in first year medical students. Soc Sci Med 1986;22:593-598.

20. Maddux JF, Hoppe SK, Costello RM: Psychoactive substance use among medical students. Am J Psychiatry 1986:143:187191.

21. Parkerson G, Eisenson HJ, Munning KA, et al: A health promotion program for medical students. J Med Ed 1988;63:722723.

22. Wolf FM, Ulman JG, Saltzman GA, et al: Allocation of time and perceived coping behavior of first-year medical students. $J$ Med Educ 1980;55:956-958.

23. Wolf TM, Faucett JM, Randall HM, et al: Graduating medical students' ratings of stresses, pleasures, and coping strategies. J Med Educ 1988;63:636-642.

24. Colley A: Sex roles and expectations of leisure behavior. Leisure Studies 1984;3:335-341.

25. Shank JW: An exploration of leisure in the lives of dual career women. $J$ Leisure Res 1986;18:300-319. 


\section{HYPERTENSION IS USUALLY SILENT}

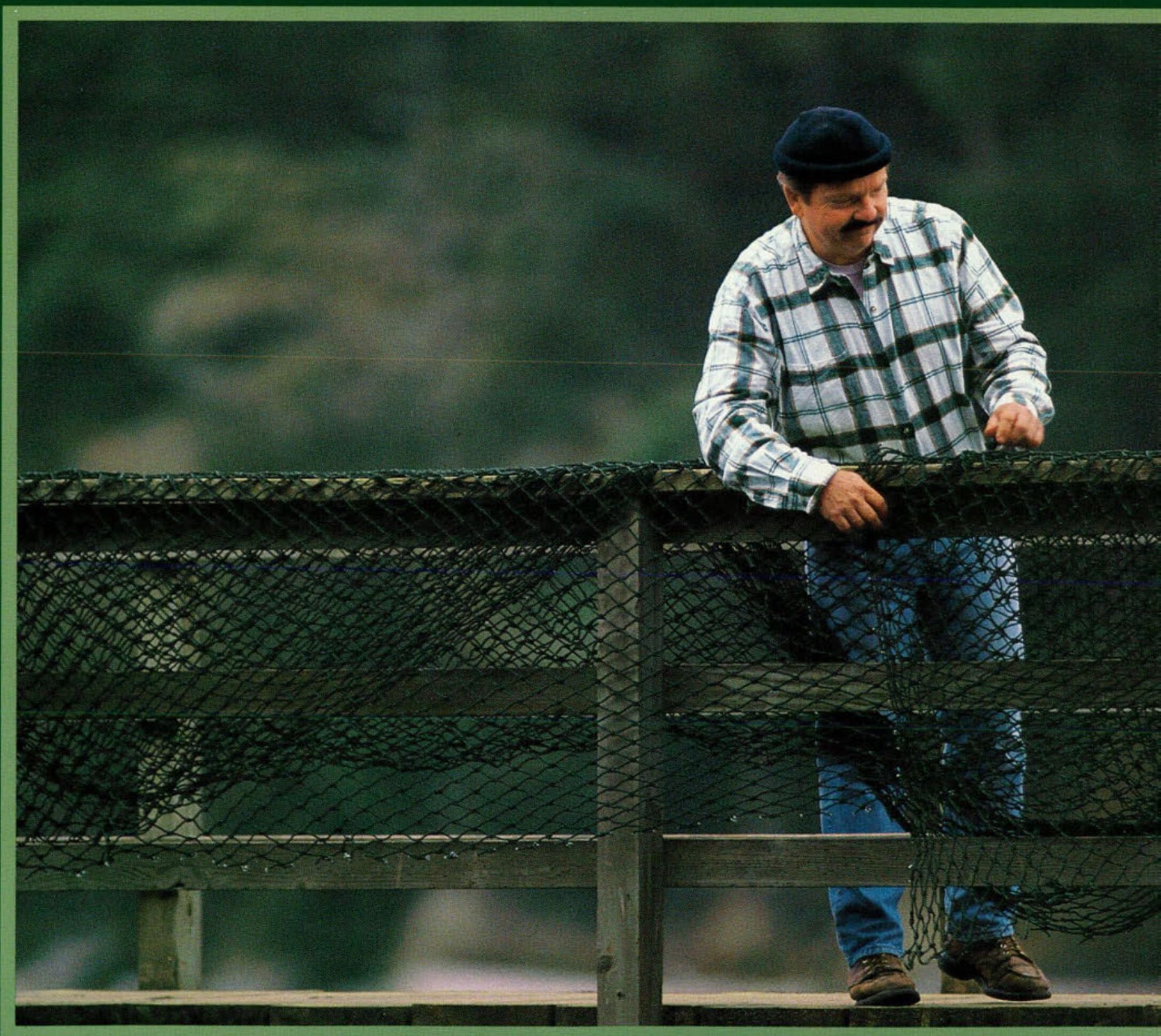




\section{THERAPY THAT MAY BE AS SILENT AS HYPERTENSION ITSELF}

VASOTEC $^{8}$ (Enalapril Maleate, MSD) is generally well tolerated and not characterized by certain undesirable effects associated with selected agents in other antihypertensive classes.

VASOTEC is contraindicated in patients who are hypersensitive to this product and in patients with a history of angioedema related to previous treatment with an ACE inhibitor.

A diminished antihypertensive effect toward the end of the dosing interval can occur in some patients.

For a Brief Summary of Prescribing Information, please see the last page of this advertisement.

Copyright ๑ 1989 by Merck \& Co., INC. 

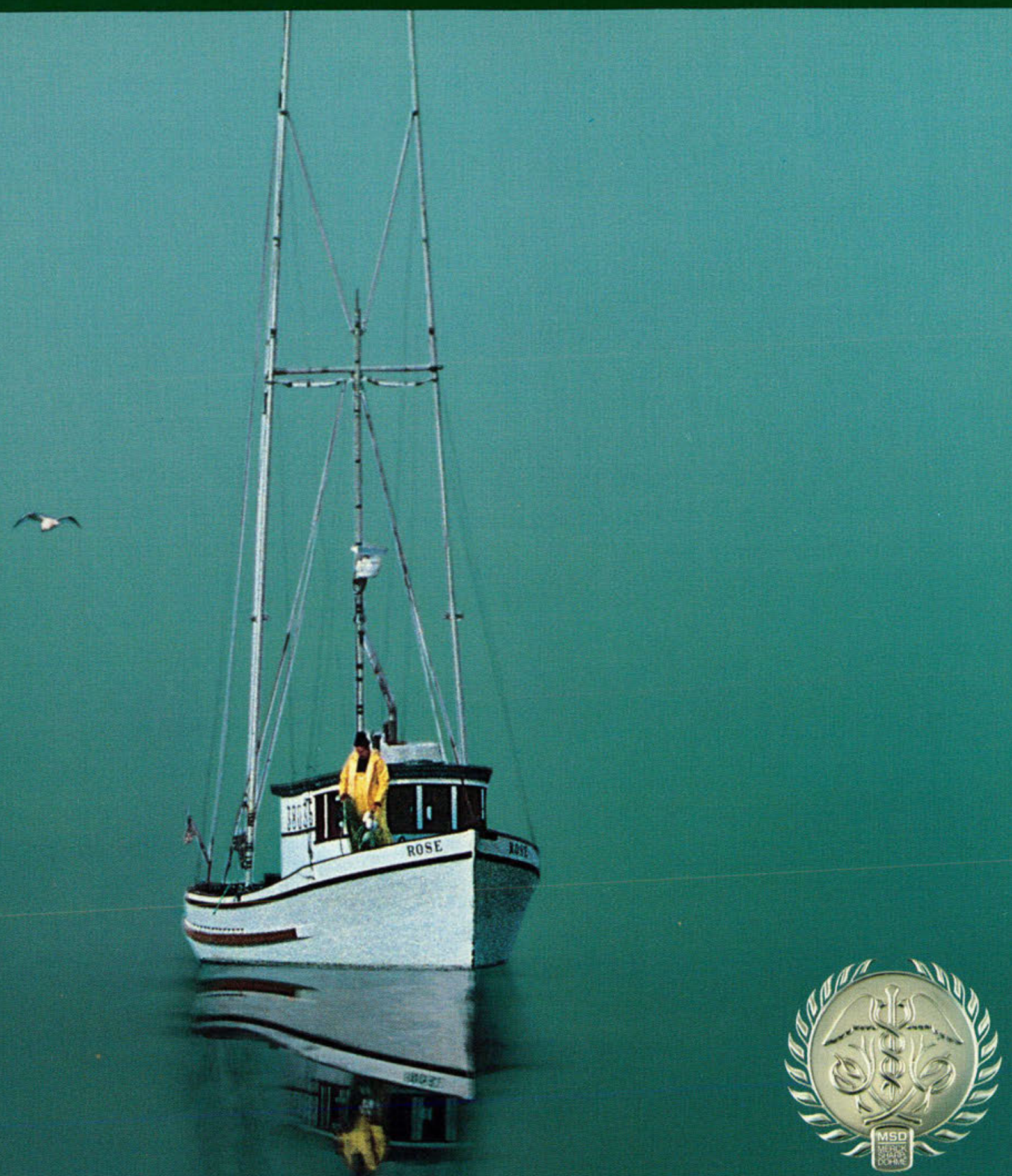

FOR MANY HYPERTENSIVE PATIENTS

ONCE-A-DAY

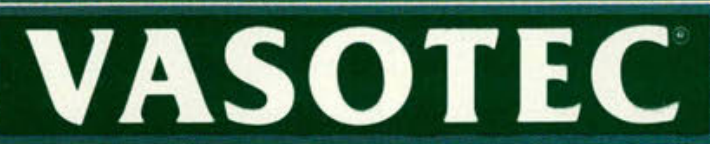

(ENALAPRIL MALEATE MSD) 


\section{VASOTEC (ENALAPRIL MALEATE $\mid$ MSD)}

VASOTEC is available in 2.5-mg, 5-mg, 10-mg, and 20-mg tablet strengths.

Contraindications: VASOTEC (Enalapril Maleate, MSD) is contraindicated in patients who are hypersensit
this product and in patients with a history of angioedema related to previous treatment with an ACE inhibitor. Warnings: Angioedema Angioedema of the tace, extremities, lips, tongue, glottis, and/or larynx has been reported in and the patient carefully observed until the swelling disappears. In instances where swelling has been confined to the relieving symptoms. Angioedema associated with laryngeal edema may be falal Where there is involvement of the tongue, glottis, or larynx likely to cause airway obstruction, appropriate therapy, e.g., subcutaneous
epinephrine solution $1: 1000(0.3 \mathrm{~mL}$ to $0.5 \mathrm{~mL})$, should be promptly adminisfered. (See ADVERSE

Hypotension: Excessive hypotension is fare in uncomplicated hypertensive patients treated with VASOTEC alone
Patients with heart failure given VASOTEC commonly have some reduction in blood pressure, especially with the first dose, but discontinuation of therapy for continuing symptomatic bypotension usualy is not necessary when dosing instructions are followed: caution should be observed when initiating therapy. (See DOSAGE AND ADMINISTRA-
TION.) Patients at risk tor excessive hypotension, sometimes associaled with oliguria and/or progressive azotemia and rarely with acute renal failure and/or death, irclude those with the following conditions or characteristics. heart tailure, hyponatremia, high-dose diuretic therapy, recent intensive diuresis or increase in diuretic dose, renal dialysis
or severe volume and $/$ or salt depletion of any etiology. It may be advisable to eliminate the diuretic (except in patients with heart failure), reduce the diuretic dose, or increase salt intake cautiously before initiating therapy with VASOTEC
in patients at risk for excessive hypotension who are able to tolerate such adjustments. (See PRECAUTIONS, Oryg interactions and ADVERSE REACTIONS.) In patients at risk for excessive hypotension, therapy should be started unde: very close medical supervision and such patients should be followed closely for the first two weeks of treatment and whenever the dose of enalapril and/or diuretic is increased. Similar considerations may apply to patients with ischinfarction or cerebrovascular accident. If excessive hypotension occurs, the patient should be placed in the supine contraindication to further doses of VASOTEC, which usually can be given without difficulty once the blood pressure

Neutropenia/Agranuilocytosis: Another ACE inhibitor, captopril, has been shown to cause agranulocytosis and bone marrow depression, rarely in uncomplicated patients but more trequently in patients with renal impairment, especially enalapril does not cause agranul ocytosis at similar rates. Foreign marketing experience has revealed several cases chease and renal disease should be considered

system, changes in renal function may be anticipated in susceptible individuals. In patients with severe heart tailure whose renal function may depend on the activity of the renin-angiotensin-aldosterone system, treatment with ACE
inhibitors, including VASOTEC, may be associaled with oliguria and/or progressive azotemia and rarely with acute

In clinical studies in hypertensive patients with unilateral or bilateral renal artery stenosis. increases in blood urea nitrogen and serum creatinine were observed in $20 \%$ of patients. These increases were almost always reversible upon
discontinuation of enalapril and/or diuretic therapy. In such patients, renal function should be monitored during the

Some patients with hypertension or heart failure with no apparent preexisting renal vascular disease have developed increases in blood urea and serum creatinine, usually minor and transient, especially when VASOTEC has been given
concomitantly with a diuretic. This is more likely to occur in patients with preexisting renal impairment. Dosage Evaluation of patients with hypertension or heart failure should always include assessment of renal

Hyperkalemia: Elevated serum potassium ( $>5.7 \mathrm{mEQ} / \mathrm{L}$ ) was observed in approximately $1 \%$ of hypertensive patients was a cause of discontinuation of therapy in $0.28 \%$ of hypertensive patients. In clinical trials in heart tallure, hyperkalemia was observed in $3.8 \%$ of patients, but was not a cause for discontinuation.

Risk factors for the development of hyperkalemia include renal insufficiency, diabetes mellitus, and the concomitant use of potassium-sparing diuretics, potassium supplements, and/or potassictions.)
should be used cautiously, if at all, with VASOTEC. (See Drug interactions.

Surgery/Anesthesia: In patients undergoing major surgery or during anesthesia with agents that produce hypotension
enalapril may block angiotensin II formation secondary lo compensatory renin release If hypotension occurs and is considered to be due to this mechanism, it can be corrected by volume expansion.

Information for Patients:

Angioedema: Angioedema, including laryngeal edema may occur especially following the first dose of enalapt: ing of face, extremities, eyes, lips, tongue, difticulty in swallowing or breathing) and to take no more drug until they
have consulted with the prescribing phisician.

Hypotension: Patients should be cautioned to report lightheadedness, especially during the first few days of therapy
actual syncope occurs, the patients should be told to discontinue the drug until they have consulted with the prescrib-

All patients should be cautioned that excessive perspiration and dehydration may lead to an excessive fall in blood
pressure because of reduction in fluid volume. Other causes of volume depletion such as vomiting or diarrhea may also lead to a tall in blood pressure: patients should be advised to consult with the physician

Hyperkalemia: Patients should be told not to use salt substitutes containing potassium without consulting their Neutropenia: Patients should be told to report promptly any indication of infection (e.g. Sore throat, fever) which may be a sign of neutropenia.

NOTE: As with many other drugs, certain advice to patients being treated with enalapril is warranted. This information intended effects.

Hypotension: Patients on Diuretic Therapy: Patients on diuretics and especially those in whom diuretic therapy was with enalaprit. The possibility of hypotensive effects with enalapril can be minimized by either discontinuing the
with diuretic or increasing the salt intake prior to initiation of treatment with enalaprit. If it is necessary to continue the
diuretic, provide close medical supervision after the initial dose for at least two hours and until blood pressure has
stabilized for at least an additional hour. (See WARNINGS and DOSAGE AND ADMINISTRATION)

Agents Causing Renin Release: The antihypertensive effect of VASOTEC is augmented by antihypertensive agents that

Other Cardiovascular Agents: VASOTEC has been used concomitantly with beta-adrenergic-blocking agents, methyl-
dopa, nitrates, calcium-blocking agents, hydralazine, prazosin, and digoxin without evidence of clinically significan dopa, nitrates, calcium-

Agents Increasing Serum Potassium: VASOTEC attenuates potassium loss caused by thiazide-type diuretics Potassium-sparing diuretics (e.g., spironolactone, triamterene, or amiloride), potassium supplements,
potassium-containing salt substitutes may lead to significant increases in serum potassium. Therefore, if concom
ant use of these agents is indicated because of demonstrated hypokalemia, they should be used with caution and tant use of these agents is indicated because of demonstrated hypokalemia, they should be used with caution and
with frequent monitoring of serum potassium. Potassium-sparing agents should generally not be used in patients
with heart tailure receiving VASOTEC Lithium: Lithium toxicity has been rep

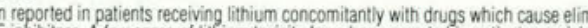
concomitant VASOTEC and lithium and were reversible upon discontinuation of both drugs. It is recommended that Pregnancy-Category $C$. There was no fetotoxicity or teratogenicity in rats treated with up $10200 \mathrm{mg} / \mathrm{kg} /$ day of enalapri
$(333$ times the maximum human dose) Fetotoxicity, expressed as a decrease in average fetal $(333$ times the maximum human dose) Fetotoxicity, expressed as a decrease in average fetal weight, occurred
in rats given $1200 \mathrm{mg} / \mathrm{kg} / \mathrm{day}$ of enalapril but did not occur when these animals were supplemented with saline Enalagn was not teratogenic in raboits. However, maternal and tetal toxicity occurred in some rabbits at doses of
$1 \mathrm{mg} / \mathrm{kg} / \mathrm{day}$ or more. Saline supplementation prevented the maternal and fetal toxicity seen at doses of 3 and $10 \mathrm{mg}$
$\mathrm{kg} /$ day, but not at $30 \mathrm{mg} / \mathrm{kg} /$ day

Radioactivity was found to cross the placenta following administration of labeled enalapril to pregnant hamsters

There are no adequate and well-controlled studies of enalapril in pregnant women. However, data are available that
show enalapril crosses the human placenta. Because the risk of fetal toxicity with the use of ACE inhibitors has nol been clearly defined, VASOTEC* (Enalapril Maleate, MSO) should be used during pregnancy only if the potential benent justifies the potential risk to the letus.

Postmarketing experience with all ACE inhibitors thus far suggests the following with regard to pregnancy outcome fetal exposure during the second and third trimesters of pregnancy has been associated with fetal and neonatal mo: bidity and mortality.

When ACE inhibitors are used during the later stages of pregnancy, there have been reports of hypotension and decreased renal perfusion in the newborn. Oligohydramnios in the mother has also been reported, presumably repre-

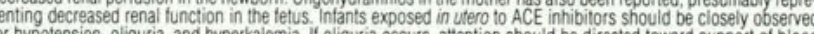

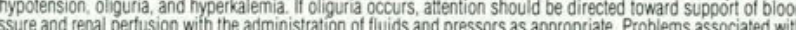
prematurity such as patent ductus arteriosus have occurred in association with maternal use of ACE inhibitors, but s not clear whether they are related to ACE inhibition, maternal hypertension, or the underlying prematurity.

nowng Morthers: Milk in lactating rats contains radioactrvity following administration of 'e C enalapril maleate. It is no be exercised when VASOTEC is given to a nursing mothet.

.

Adverse Reactions: VASOTEC has been evaluated for safely in more than 10,000 patients, including over 1000 rials involving 2987 patients.

AYPERTENSION: The most frequent clinical adverse experiences in controlled trials were: headache (5.2\%), dizziness

Other adverse experiences occurring in greater than $1 \%$ of patients treated with VASOTEC in controlled clinical trials HEART FACURE. The most frequent clinical adverse experiences in both controlled and uncontrolled trials were: dizzdiarthea $(2.1 \%)$.

Other adverse experiences occurring in greater than $1 \%$ of patients treated with VASOTEC in both controlled and

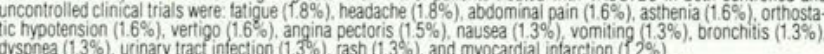
Other serious clinical adverse experiences occurring since the drug was marketed or adverse experiences occurring category:

Cardiovascular: Cardiac arrest: myocardial infarction or cerebrovascular accident, possibly secondary to excessive
hypotension in high-risk patients (see WARNINGS. Hypotension): pulmonary embolism and intarction; pulmonary hypotension in high-risk patients (see WARNINGS, Hypd

Digestive: lleus, pancreatitis, hepatitis (hepatocellular or cholestatic jaundice), melena, anorexia, dyspepsia, conMusculoskeletal: Muscle cramps

Nervous/Psychiatric: Depression, confusion, ataxia, somnolence, insomnia nervousness, paresthesia

Urogenital: Renal failure, oliguria, renal dystunction (see PRECAUTIONS and DOSAGE AND ADMINISTRATION). Respiratory: Bronchospasm, rhinorrhea. sore throat and hoarseness, asthma. upper respiratory intection.

Skin: Exfoliative dermatitis, toxic epidermal necrolysis. Stevens-Johnson syndrome, herpes zoster, erythema mult: .

Specia/ Senses: Blurred vision, taste alteration, anosmia, tinnitus, conjunctivitis, dry eyes, tearing A symptom complex has been reported which may include a positive ANA an elevated erythrocyle sedimentation rate, dermatologic manitestations.

Angioedema: Angioedema has been reported in patients receiving VASOTEC $(0.2 \%)$. Angioedema associated with aryngeal edema may be fatal if angioedema of the tace, extremities, lips, tongue, glottis, and dor larynx occurs. treat: Aypotension: In the hypertensive patients, hypotension occurred in $0.9 \%$ and syncope occurred in $0.5 \%$ of patients apy in $0 . \%$ of hypertensive patients. In heart tailure patients, hypotension occurred in $67 \%$. 7 and syncope occurred $22 \%$ of patients. Hypotension or syncope was a cause for discontinuation of therapy in $19 \%$ of patients with heart Clinical Laboratory Test Findings

Serum Electroilyes: Hyperkalemia (see PRECAUTIONS), hyponatremia

Creatinine, Blood Urea Nitrogen: In controlled clinical trials, minor increases in blood urea nitrogen and serum creatinine, reversible upon discontinuation of therapy. were observed in about $0.2 \%$ of patients with essential hypertenpatients with renal artery stenosis. (See PRECAUTIONS) in patients with heart failure who were also receivin continuation of VASOTEC and/or other concomitant diuretic therapy, were observed in about $11 \%$ of patients . Hemoglobin and Hematocrit: Small decreases in hemoglobin and hematocrit (mean decreases of approximatel VASOTEC but are rarely of clinical importance unless another cause of anemia coexists. In clinical trials. less than Other (Causal Relationship Unknown): In marketing experience, rare cases of neutropenia, thrombocylopenia, and bone martow depression have been reported. A few cases of hemolysis have been reported in patients with G6P ives Function Tests: Elevations of liver enzymes and/or serum bilirubin have occurred. Dosage and Administration: Hypertension: in patients who are currently being treated with a diuretic, symptomatic ypotension occasionally may occur following the initial dose of VASOIEC The diuretic should, if possible, be disWARNINGS.) if the patient's blood pressure is not controlled with VASOTEC alone, diuretic therapy may be resumed If the diuretic cannot be discontinued an initial dose of $2.5 \mathrm{mg}$ should be used under medical supervision for at leas TIONS, Orug Interactions

The recommended initial dose in patients not on diuretics is $5 \mathrm{mg}$ once a day. Dosage should be adjusted according divided doses. In some patients treated once daily, the antihypertensive effect may diminish toward the end of the dosing interval. In such patients, an increase in dosage or twice-daily adinin

Concomitant administration of VASOTEC with potassium supplements, potassium salt substitutes, or potassiumsparing diuretics may lead to increases of serum potassium (see PRECAUTIONS)

Dosage Adjustment in Hypertensive Patients with Renal impairment: The usual dose of enalaprit is recommended for wath creatinine clearance $\leq 30 \mathrm{~mL} / \mathrm{min}$ (serum creatinine $\geq 3 \mathrm{mg} / \mathrm{dL}$ ), the first dose is $2.5 \mathrm{mg}$ once daily. The dosage may be titrated upward until blood pressure is controlled or to a maximum of $40 \mathrm{mg}$ daily.

Heart Failure: VASOTEC is indicated as adjunctive therapy with diuretics and digitalis. The recommended starting upervision for at least two hours and until blood pressure has stabilized for at least an additional hour. (See WARN diminish the likelihood of hypotension. The appearance of hypotension after the initial dose of VASOIFC which may preclude subsequent careful dose titration with the drug following effective management of the hypotension. The usual therapeutic dosing range for the treatment of hearf tailure is 5 to $20 \mathrm{mg}$ daily given in two divided doses. The maximum daily dose is $40 \mathrm{mg}$. Once-daily dosing has been effective in a controlled study, but nearly all patients in twice-daliy dosing In addition, in a placebo-controlled study which demonstrated reduced mortality in patients with severe heart tailure (NYHA Class iN), patients were treated with 2.5 to $40 \mathrm{mg}$ per day of VASOTEC. a Imost always
administered in two divided doses. (See CLINICAL PHARMACOLOGY, Pharmacodnamics and Clinical Effects) Dosage may be adjusted depending upon clinical or hemodynamic response. (See WARNINGS.) Dosage Adjustment in Patients with Heart Failure and Renal impairment or Hyponatremia: In patients with heart failure ated at $25 \mathrm{mg}$ daily under close medical supervision. (See DOSAGE AND ADMINISTRATION. Hear? bild. then $5 \mathrm{mg}$ b.i.d. and higher as needed. usualiy at intervals of four days or more, if at the timg of dosage adjustment there is not excessive hypotension or significant deterioration of renal function. The maximum daily dose is $40 \mathrm{mg}$.

For more detailed information, consult your MSD Representative or see Prescribing information, Merck
Sharp \& Dohme, Dinsion of Merck \& Co. INC. West Point. PA 9486 